\title{
The Model of Diffusion of Knowledge on Industry 4.0 in Marshallian Clusters
}

\author{
Irena Pawłyszyn ${ }^{1, *(\mathbb{D}}$, Marek Fertsch ${ }^{1}$, Agnieszka Stachowiak ${ }^{1, *} \mathbb{D}$, Grzegorz Pawłowski ${ }^{2} \mathbb{D}$ and \\ Joanna Oleśków-Szłapka ${ }^{1}$ (D) \\ 1 Institute of Logistics, Faculty of Management Engineering, Poznan University of Technology, \\ 61-131 Poznan, Poland; marek.fertsch@put.poznan.pl (M.F.); \\ joanna.oleskow-szlapka@put.poznan.pl (J.O.-S.) \\ 2 Faculty of Finance and Banking, WSB University Poznan, 61-895 Poznan, Poland; \\ grzegorz.pawlowski@wsb.poznan.pl \\ * Correspondence: irena.pawlyszyn@put.poznan.pl (I.P.); agnieszka.stachowiak@put.poznan.pl (A.S.)
}

Received: 23 April 2020; Accepted: 5 May 2020; Published: 7 May 2020

check for updates

\begin{abstract}
Industry 4.0 is perceived as the innovative approach to manufacturing management, thanks to which enterprises gain efficiency and improve competitiveness. The research on Industry 4.0 carried and published refer to the scope of solutions recognized as Industry 4.0 and the level of recognition and implementation of solutions within Industry 4.0. The conclusion from the latter is that enterprises, though striving for innovation and improvement, have no knowledge on solutions available. Hence, the research goal of the paper was to identify the level of knowledge on Industry 4.0 among enterprises and analyze the mechanism of knowledge diffusion. The subjects of research were enterprises in Marshallian clusters, as they are linked, which may contribute to knowledge diffusion and Industry 4.0 solutions dissemination. Research methodology implemented included three stages, namely knowledge level recognition, Industry 4.0 knowledge diffusion model development, and validation of the model with case-based simulation. The conclusions, based on simulation results, refer to mechanism and the most important parameters of knowledge on Industry 4.0 diffusion.
\end{abstract}

Keywords: Industry 4.0; innovation; diffusion of knowledge; Marshallian cluster

\section{Introduction}

Contemporary companies cooperate to benefit from shared resources and synergy. Due to the cooperation they learn from each other, sharing knowledge on technology, market, and customers' needs. As nowadays the driver of technology development is the Industry 4.0 approach, companies disseminate their knowledge and experience on dealing with issues as well.

The goal of this work is to develop the model of diffusion of Industry 4.0 solutions in Marshallian clusters. The object of the research-Industry 4.0-was selected because of growing interest from companies in the benefits it can bring. The subject of the research-Marshallian clusters-was selected because the authors believe that absorption of new solutions is enhanced by cooperation and clusters are structures based on cooperation. The approach implemented in the research is inspired by innovation diffusions models. The methods and tools within the Industry 4.0 scope are generally innovative, based on recent technology development. Hence, the authors believe that mechanisms and drivers of innovation diffusion can be used in the analysis of the Industry 4.0 diffusion process. An organizational perspective is adopted, because it is entire businesses that acquire knowledge and belief that it is necessary to implement Industry 4.0 solutions. The Industry 4.0 knowledge diffusion model is based on a six-stage scheme for the diffusion of innovation, presented by Rogers [1]. It is customized with 
conclusions arising from multifaceted analysis of literature and identification of relationships between selected parameters of organizations cooperating in a cluster. The paper's structure reflects the research process presented in the Materials and Methods section. To comprehensively present research results, the paper is organized as follows: The second section introduces the methodology implemented, presenting methods and research tools used in the predesigned sequence. The third includes critical literature review results and briefly presents the most important aspects of Industry 4.0, innovation diffusion, and Marshallian cluster structure. The fourth section presents the model developed with discussion of its elements and structure. The fifth includes the validation procedure. The next sections cover the discussion and authors' conclusions. The developed models will allow researchers and practitioners to understand the essence of the Industry 4.0 diffusion, which in turn will stimulate this diffusion and increase the competitiveness of enterprises, as well as the spread and development of knowledge in the field of Industry 4.0.

\section{Materials and Methods}

Contemporary enterprises striving for Industry 4.0 implementation need to be open to innovation. Hence, they can benefit from numerous opportunities to develop, increase competitiveness on the local, domestic, or international market. Moreover, along with reaching ever higher stages of development, they have greater opportunities to independently create innovation. Thus, innovation implementation seems to be crucial for enterprises willing to develop. However, since innovation implementation is usually time- and cost-consuming, enterprises willing to benefit from innovation often benefit from best-practices and the experience of others. Such cooperation is enabled and enhanced by network structure. Hence, the subject of this research was enterprises that operate in network structures, namely Marshallian clusters. The research problem the paper strives to discuss is the analysis of cluster enterprises in terms of diffusion of innovation and the drivers of innovation and knowledge dissemination.

The goal of this work was to develop Industry 4.0 knowledge diffusion model. It should be emphasized that the Industry 4.0 concept is considered in an innovation. The main research problem of the subject work was the question about the reasons for the fast and effective diffusion of the Industry 4.0 concept in Marshallian clusters. Based on the problem definition the following hypothesis was formulated:

There are factors that determine the pace of Industry 4.0 knowledge diffusion in Marshallian cluster. To verify the hypothesis, the authors conducted the research to answer the research questions:

Research Question1.: What is the mechanism of Industry 4.0 knowledge diffusion in Marshallian clusters?

Research Question2.: What are the factors contributing to efficient and effective diffusion of Industry 4.0 knowledge diffusion in the Marshallian clusters?

The answers provided can not only result in an increase in theoretical knowledge about diffusion of innovation, but also support decision-making processes in relation to the development of appropriate conditions and attitudes in cluster enterprises striving for Industry 4.0 implementation.

The research process was carried out according to the plan designed to verify the hypothesis and answer research questions. It included the following stages:

(a) literature research carried out to obtain information about clusters, diffusion, and Industry 4.0;

(b) determining the criteria for selecting respondents and preparing a base of respondents;

(c) collecting and analyzing respondents' answers;

(d) building an innovation diffusion model;

(e) implementing the diffusion model in the IT environment;

(f) development of simulation scenarios;

(g) model verification;

(h) drawing conclusions. 
The research problem formulated in the work required conducting research in terms of literature query and empirical research among Marshallian cluster enterprises. The research process was divided into three stages. In the first stage, the theoretical basis was established using available literature and digital sources. The critical literature review approach was implemented and the indexed bases were included. In the second stage, surveys were conducted among a specified group of enterprises-production and also production and service companies. The CAWI (Computer-Assisted Web Interview-website assisted) and CATI (Computer-Assisted Telephone Interviewing) methods were implemented. The goal of this stage was to distinguish the main factors that are decisive in the context of the implementation of Industry 4.0 in the enterprise. The third stage was conceptual and resulted in an innovation diffusion model for Marshallian cluster development and validation. The model was validated by means of a computer simulation method implemented in $\mathrm{C}++$.

The analysis was carried out to reveal the factors favoring and slowing down the process of diffusion of innovation in Marshallian clusters.

\section{Related Work}

The Industry 4.0 concept has been disseminated for almost ten years, as it was first introduced in 2011. Since that time Industry 4.0 has been defined from many perspectives and with various precision. Selected examples of the definitions are presented in the Table 1.

Table 1. Definitions of the Industry 4.0 concept.

\begin{tabular}{|c|c|}
\hline Source/Author & Definition \\
\hline High-Tech Strategy 2020 plan & $\begin{array}{l}\text { A paradigm shift from centralized to decentralized smart manufacturing } \\
\text { and production. Smart production becomes the norm in a world where } \\
\text { intelligent ICT-based machines, systems, and networks are capable of } \\
\text { independently exchanging and responding to information to manage } \\
\text { industrial production processes. }\end{array}$ \\
\hline McKinsey and Company & $\begin{array}{l}\text { The next phase in the digitization of the manufacturing sector, driven by } \\
\text { four disruptions: the astonishing rise in data volumes, computational } \\
\text { power and connectivity, especially new low-power wide-area networks; the } \\
\text { emergence of analytics and business-intelligence capabilities; new forms of } \\
\text { human-machine interaction, such as touch interfaces and augmented-reality } \\
\text { systems; and improvements in transferring digital instructions to the } \\
\text { physical world, such as advanced robotics and 3-D printing }\end{array}$ \\
\hline Industrie 4.0 Platform & $\begin{array}{l}\text { The intelligent networking of machines and processes for industry with the } \\
\text { help of information and communication technology }\end{array}$ \\
\hline $\begin{array}{l}\text { The Industrial Internet } \\
\text { Consortium }\end{array}$ & $\begin{array}{l}\text { The integration of complex physical machinery and devices with networked } \\
\text { sensors and software, used to predict, control, and plan for better business } \\
\text { and societal outcomes }\end{array}$ \\
\hline $\begin{array}{l}\text { Boston Consulting Group } \\
\text { (BCG) }\end{array}$ & $\begin{array}{l}\text { A new digital industrial technology that is powered by nine foundational } \\
\text { technology advances: big data and analytics, simulation, autonomous } \\
\text { robots, horizontal and vertical system integration, the industrial internet of } \\
\text { things, cybersecurity, the cloud, additive manufacturing, augmented reality }\end{array}$ \\
\hline $\begin{array}{l}\text { A. Merkel, OECD Conference } \\
\text { (2014) }\end{array}$ & $\begin{array}{l}\text { The comprehensive transformation of the whole sphere of industrial } \\
\text { production through the merging of digital technology and the internet with } \\
\text { conventional industry. In short, everything in and around a manufacturing } \\
\text { operation (suppliers, the plant, distributors, even the product itself) is } \\
\text { digitally connected, providing a highly integrated value chain }\end{array}$ \\
\hline $\begin{array}{l}\text { M. Brettel, N. Friederichsen. } \\
\text { M. Keller, M. } \\
\text { Rosenberg (2014) }\end{array}$ & $\begin{array}{l}\text { A digitalization of product and processes through increased intelligence. } \\
\text { It focuses on the establishment of intelligent products and production } \\
\text { processes }\end{array}$ \\
\hline
\end{tabular}

R. Schmidt, M. Möhring, R.

Härting, C. Reichstein, P.

The embedding of smart products into digital and physical processes

Neumaier, J. Jozinović (2015) 
Table 1. Cont.

\begin{tabular}{|c|c|}
\hline Source/Author & Definition \\
\hline $\begin{array}{l}\text { C. Toro, I. Barandiaran, J. } \\
\text { Posada (2015) }\end{array}$ & $\begin{array}{l}\text { An integration of complex machinery and devices, with sensor and software } \\
\text { networks, used to predict, control, and improve plan business and results in } \\
\text { society }\end{array}$ \\
\hline $\begin{array}{l}\text { M. Hermann, T. Pentek, B. } \\
\text { Otto (2016) }\end{array}$ & $\begin{array}{l}\text { A holistic system of information technologies, people, machines, and tools, } \\
\text { where cyber-physical systems (CPS) monitor physical processes, create a } \\
\text { virtual copy of the physical world and make decentralized decisions }\end{array}$ \\
\hline $\begin{array}{l}\text { A. Sanders, Ch. } \\
\text { Elangeswaran, J. } \\
\text { Wulfsberg (2016) }\end{array}$ & $\begin{array}{l}\text { An industrial revolution applying the principles of CPS, Internet, } \\
\text { and future-oriented technologies and smart systems with enhanced } \\
\text { human-machine interaction paradigms }\end{array}$ \\
\hline $\begin{array}{l}\text { J. Qin, Y. Liu, R. } \\
\text { Grosvenor (2016) }\end{array}$ & $\begin{array}{l}\text { A concept of manufacturing which consists of exchanged information and } \\
\text { controlled machines and production units acting autonomously and } \\
\text { intelligently in interoperable }\end{array}$ \\
\hline $\begin{array}{l}\text { R.Y. Zhong, X. Xu, E. } \\
\text { Klotz, S.T. Newman (2017) }\end{array}$ & $\begin{array}{l}\text { A holistic system combines embedded production system technologies with } \\
\text { intelligent production processes to pave the way for a new technological age } \\
\text { that will fundamentally transform industry value chains, production value } \\
\text { chains, and business models }\end{array}$ \\
\hline $\begin{array}{l}\text { C. Santos, A. Mehrsai, A.C. } \\
\text { Barros, M. Araújo, E. } \\
\text { Ares (2017) }\end{array}$ & $\begin{array}{l}\text { A comprehensive concept as well as a new trend in manufacturing (and } \\
\text { relevant sectors) based on the integration of a set of technologies that enable } \\
\text { ecosystems of intelligent, autonomous, as well as decentralized factories } \\
\text { and integrated product-services }\end{array}$ \\
\hline $\begin{array}{l}\text { A. Wortmann, B. } \\
\text { Combemale, O.A. } \\
\text { Barais (2017) }\end{array}$ & $\begin{array}{l}\text { A vision of manufacturing in which smart, interconnected production } \\
\text { systems optimize the complete value-added chain to reduce cost and } \\
\text { time-to-market. It is the smart factory of the future, whose successful } \\
\text { deployment requires solving challenges from many domains }\end{array}$ \\
\hline J. Lu (2017) & $\begin{array}{l}\text { An integrated, adapted, optimized, service-oriented, and interoperable } \\
\text { manufacturing process which is correlated with algorithms, big data, } \\
\text { and high technologies }\end{array}$ \\
\hline
\end{tabular}

Source: [2].

All the definitions refer to solutions of innovative character and stress the need for their implementation in contemporary companies. However, such implementation requires knowledge. Diffusion of knowledge and innovation is a topic quite often described and discussed from various perspectives by many researchers [1,3-5].

The theory of innovation diffusion proposed by Rogers [6] indicates that innovations spread through certain channels and become adopted by the social system after a period of time. Accordingly, the process of innovation diffusion involves four major elements, namely innovations, time, communication channels, and a social system.

Innovations diffuse through segmented networks of knowledge that limit the flow of knowledge from any one technological domain to any other. There are also innovations which become the technological "ancestors" for a lineage of innovations that are located in distant (relative to the original) technological domains. They serve as bridges that eventually link different technological domains [7].

Innovation has been described as a key factor, while explaining the survival and competitive advantage of firms $[8,9]$. Therefore, scholars and practitioners agree on the positive effect that the acquisition, dissemination, and utilization of new knowledge has on the innovative performance of firms [10]. Innovation is one of the main economic activities that leads a company to organizational success and high results, independently of its size and the sector in which it operates [11].

Hodgson [12] affirmed that organizations should seek "new fields of knowledge" in order to accelerate the expansion of their "frontiers of science and technology" and to cope with the requirements of the technological renovation process. 
The number of papers related to "innovation model" and "innovation models" based on the Web of science database is 1386 papers. Their distribution within years 1996-2020 is shown in Figure 1 and main research areas in Figure 2. It can be seen that the main research domains are business economics, engineering, and computer science.

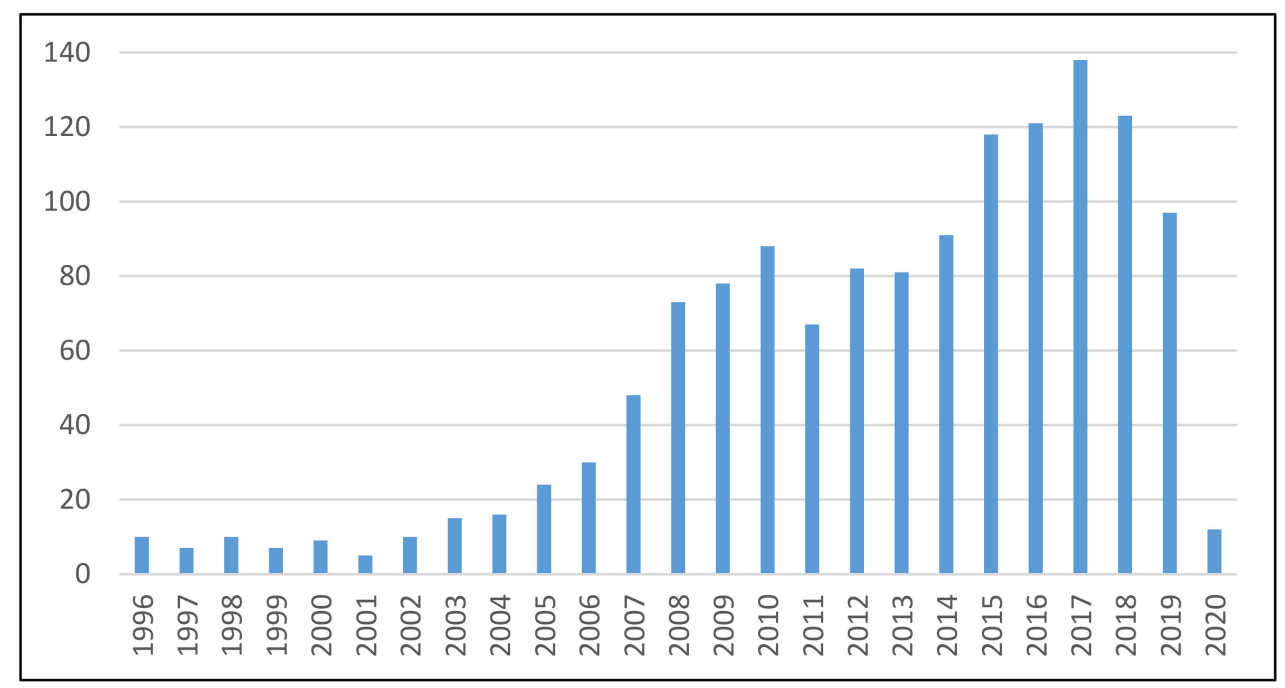

Figure 1. The number of papers related to innovation models between 1996-2020 based on the WoS (Web of Science) database.
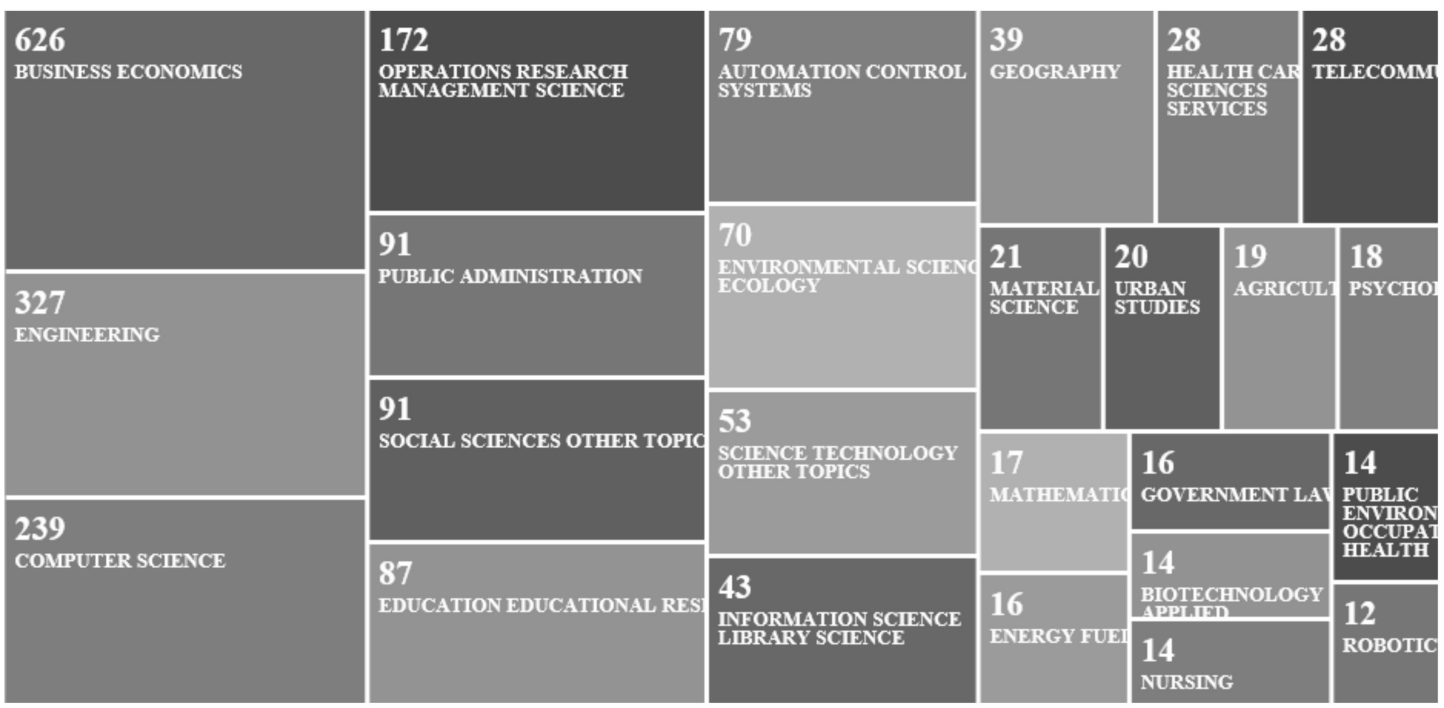

Figure 2. Research areas of papers related to innovation models based on the WoS database.

Collaboration initiatives are not new strategies for organizations seeking to increase their innovation capacity [13]. Already in the 1990s, Rothwell [14] discussed that the fifth-generation innovation process models had to be focused on the cooperation and the joint development of innovation outcomes.

Innovation, one of the dominant sources of competitive advantage in the long term, pursues the strategy that generates products and services with a radical new meaning, a major factor in the development of society and advanced economies across different nations that, respectively to its ability to feed over time a continuous development of innovation, determines the economic and technological supremacy in the global market. A technological innovation leads inevitably to an innovation from the organizational point of view of the company. 
The level of agreement and the level of trust are crucial dimensions in innovation processes. A successful innovator first and foremost focuses on trust, i.e., on the key risks of the actors and on understanding their areas of relevance [15].

However, most SMEs (Small and Medium Enterprises) do not follow a systematic innovation process or have difficulty giving this process its proper structure [16]. Smith et al. [17] found that one of the main factors influencing organizations' ability to manage innovation is directly related to their ability to manage the innovation process, mostly due to the generation of a structured innovation idea, the selection of proper techniques for idea evaluation, and the definition of suitable implementation mechanisms.

Due to the divergent development of these approaches, scholars are hardly merging the characteristics of the innovation process, the network effects, and the characteristics of the participant organizations. Lastly, while it is true that the literature has found positive correlations between collaborative networked actions and the innovativeness of companies, current trends are redefining the way innovation outcomes are conceived and developed [18].

Hence, mainly three actions have to be considered to support and encourage the intensification of the innovativeness degree in SMEs: (1) identify the competences required by SMEs while carrying out innovation processes in collaborative environments; (2) recognize and characterize collaborative network structures that will increase the performance of SMEs carrying out the innovation process; and (3) define a framework to improve the overall innovation capacity of SMEs. Consequently, as portrayed in Figure 3, the generation of a conceptual framework assessing these three actions will ease up the effort of recognizing those determinants positively affecting the innovation performance of SMEs.

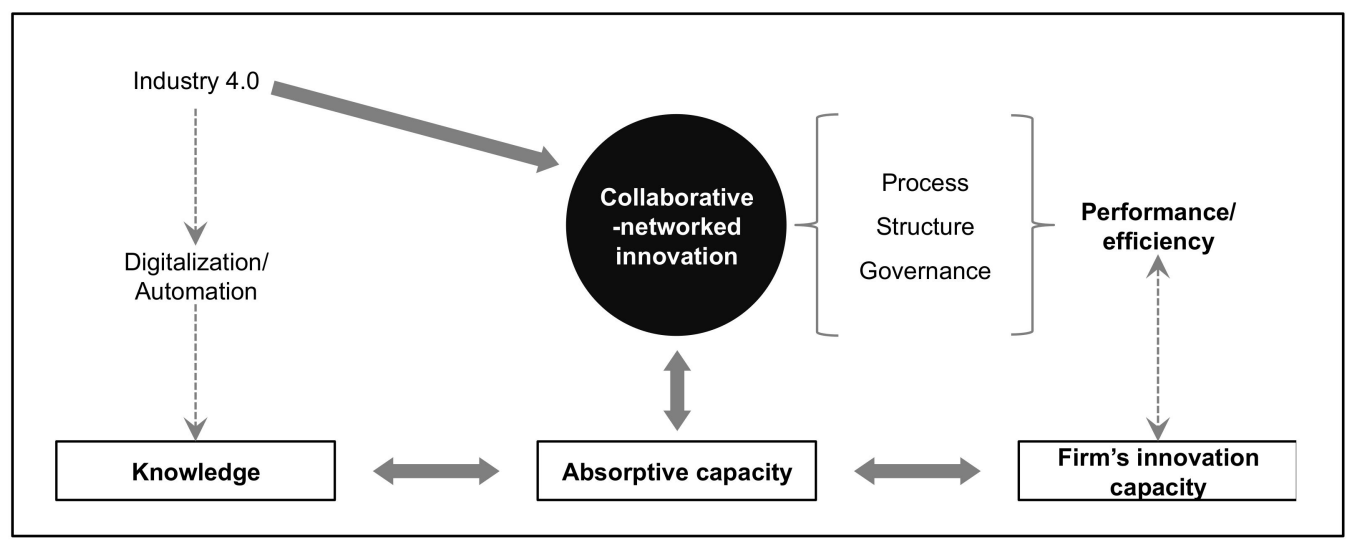

Figure 3. Research framework for collaborative networked innovation considering Industry 4.0.

Knowledge is the main transaction unit flowing through the structures of innovation networks. The knowledge-based view of the firm $[19,20]$ discusses that accessing external knowledge is required to improve the efficiency of innovations. Empirical studies suggest that the participation of organizations in innovation networks will not only speed the innovation process, but also bring them closer to obtaining new knowledge [21-23].

Entering the automatized era, authors discuss that the dispersion of knowledge will increase and also an intensification of price competition has to be expected [24]. Thus, concepts like agile innovation or agile innovation process are emerging to respond to these new challenges $[24,25]$. However, the literature keeps analyzing the subject from an organization's perspective and not attending the innovation process and even less the network perspective.

In developing countries, successful micro-enterprises are the main driving force for employment growth, yet micro-enterprises continue to face problems of limited resources, low capacity, and lack of innovative vision. Most multilateral entities as well as small- and medium-sized enterprises (SMEs) operate in the same or interrelated fields, and geographical characteristics facilitate clustering. A cluster is a geographic concentration of interconnected companies, specialized suppliers, service providers, 
firms in related industries, training institutions, and support organizations linked around technologies or an end product within a local area or region [26]. Clustering refers to the concentration of industry, related enterprises, suppliers, service providers, and logistics infrastructure in a certain area, including academic institutions, industrial organizations, standards organizations, and other institutions and various public assets in a certain area. Companies build clusters to improve productivity while creating shared value. The establishment of a fair and free market usually requires the cooperation of many partners, the enterprise will have reliable supply, and the supplier has the motivation to improve quality and efficiency [27].

Operating in clusters, companies gain a lot of benefits in terms of cost reduction, access to networks and connections, sources of financing other than those designed for an individual company, risk reduction in carrying out own business, etc. The fundamental effect of cooperation within a group is the creation of conditions and resources (including knowledge) enabling the implementation of projects or investment which would be impossible to carry out by individual entities if they acted independently [28]. Clusters should act as orchestrators and help their members not only with setting the preconditions needed to ignite innovation process, but also support them along the innovation process phases [18].

According to the development model, clusters can be divided into: the Marshallian cluster, the hub-and-spoke, the satellite, and the state-anchored clusters. The emphasis in this article was on the Marshallian clusters. This choice was not accidental and was dictated by several aspects. In the case of the remaining types of clusters, i.e., hub-and-spoke, satellite, and state-anchored, there is (inside or outside) a parent company that has a significant impact on other entities in the cluster structure. This unit may impose relevant standards, trends, or norms of conduct on its subjects. In Marshallian clusters, however, such a unit cannot be distinguished because the enterprises operating in it are independent of each other. Another aspect taken into account was that Marshallian clusters are the type of clusters most commonly encountered in practice and are characterized by the ability to quickly adapt to changing market requirements due to the interaction and cooperation of their participants. Another important argument was the fact that Marshallian clusters are dominated by small and medium enterprises. Cluster enterprises that have similar size and potential are willing to share innovation. In addition, SMEs play a key role in national economies around the world, generating employment and value added [29]. Furthermore SMEs are the predominant form of enterprise (accounting for approximately $99 \%$ of all firms), they create the largest number of jobs, and their share in generating gross domestic product (GDP) is steadily growing, so it is worth focusing on the development of this sector of enterprises, using the opportunities cluster structures.

Nonetheless, firms, particularly SMEs, are still responding to innovation process models from past generations. This could even harm firms' evolution and deprive them of the opportunity to respond to the new challenges set by the deployment of different industry-related solutions associated with Industry 4.0.

For the description of this innovative and complex process, different synonyms exist for the term Industry 4.0, such as Smart Manufacturing, IV Industrial Revolution, Intelligent Factory, Factory of the Future, and, depending on the country of implementation, initiatives have been born for the development and dissemination of technologies underlying the Industry 4.0 paradigm [30]. Industry 4.0 provides a foundation to evaluate the possibilities of expanding the field of innovation and opening the window to operationalize innovation. According to Batz et al. [18], Industry 4.0 will allow organizations to have better control over the expected interconnections with other partners and it should enable them to shorten their reaction time to any mislead within the innovation process.

The integration of innovative communication channels, particularly those integrating different elements of the Industry 4.0 strategy, might have the potential to increase the effectiveness of communication strategies between cluster managers and SMEs and thus facilitate the creation a culture of innovation in organizations, especially in SMEs [18]. 


\section{Model: Presentation and Discussion}

Human capital creates the unique value of the enterprise and is its important source of efficiency. It is a crucial factor conditioning both the material capital of the organization and the potential of other components of intellectual capital-focusing on the needs of clients, process thinking skills, ability to develop and introduce innovation. It is employees who have the greatest impact on the introduction of positive changes in the organization, the creation of new products or services or the improvement of current processes, and this determines the future development of the company or what it lacks. It is assumed that the basic element of human capital are the managers and managers of the company, who generate the highest value of intellectual capital and determine the effectiveness of the activities of regular employees, and contribute to the dissemination of knowledge [31]. Due to that, in the model of Industry 4.0 diffusion (Figure 4 ) the stakeholders considered are the managers of enterprises operating in the Marshallian cluster, as they make decisions on taking actions striving for acquiring knowledge and implementing Industry 4.0 solutions. Knowledge about the concept, acquired by managers in the cluster, and then confirmed in the belief that they need to be implemented, should be the basis for launching changes in the organization.

In order to verify the hypotheses, the author's original innovation diffusion model was developed. This model was developed based on the course of innovation diffusion described by Rogers [1] and Bass [32], as well as on the basis of a logistic curve [33]. The relationships between the mentioned models were analyzed, and the knowledge was compiled which allowed the presentation of the model.

The model assumes that there is one enterprise-innovator (company-innovator) in the cluster that has implemented the concept of Industry 4.0. So, managers of a given enterprise are fully aware of the benefits of using a given concept, and can also transfer knowledge to managers from other enterprises in the cluster. The model assumes that the remaining enterprises in the cluster do not practice the concept (potential innovation acquirers), and therefore their managers do not have knowledge about a given innovation. Knowledge diffusion occurs due to various types of contacts and meetings of managers from the company-innovator with managers qualified as potential innovation acquirers. Managers from the potential innovation acquirers category, as a result of contact with managers from the company-innovator, transfer acquired knowledge to their companies. Along with the increase in the number of managers aware and familiar with innovation, the potential innovation acquirer company (it should be emphasized that the enterprise in a given analysis is treated as a set of its managers) is willing to implement Industry 4.0 in its own environment. Therefore, it undertakes specific actions aimed at implementing the concept. To implement innovation, an enterprise should:

(1) acquire the necessary number of convinced managers;

(2) have favorable conditions for implementing innovations;

(3) implement innovation in the company's life (time aspect).

Not going through any of the stages leaves the company in the group of potential innovation acquirers. Successful implementation of innovation places the enterprise in the group of "innovation adapters". Managers of such an enterprise are becoming successive carriers of knowledge about innovation that can pass on knowledge to other potential innovation acquirers.

The presented model is based on six-level logic. Descriptions of the individual stages of the developed model are presented below.

\subsection{Stage 1: Acquiring Information about the Industry 4.0 Concept by a Company Manager}

The first stage concerns the manager's familiarization with the Industry 4.0 concept. At this stage, the manager of the selected company learns about availability of this type of innovation. There are various communication channels through which managers can familiarize themselves with Industry. 


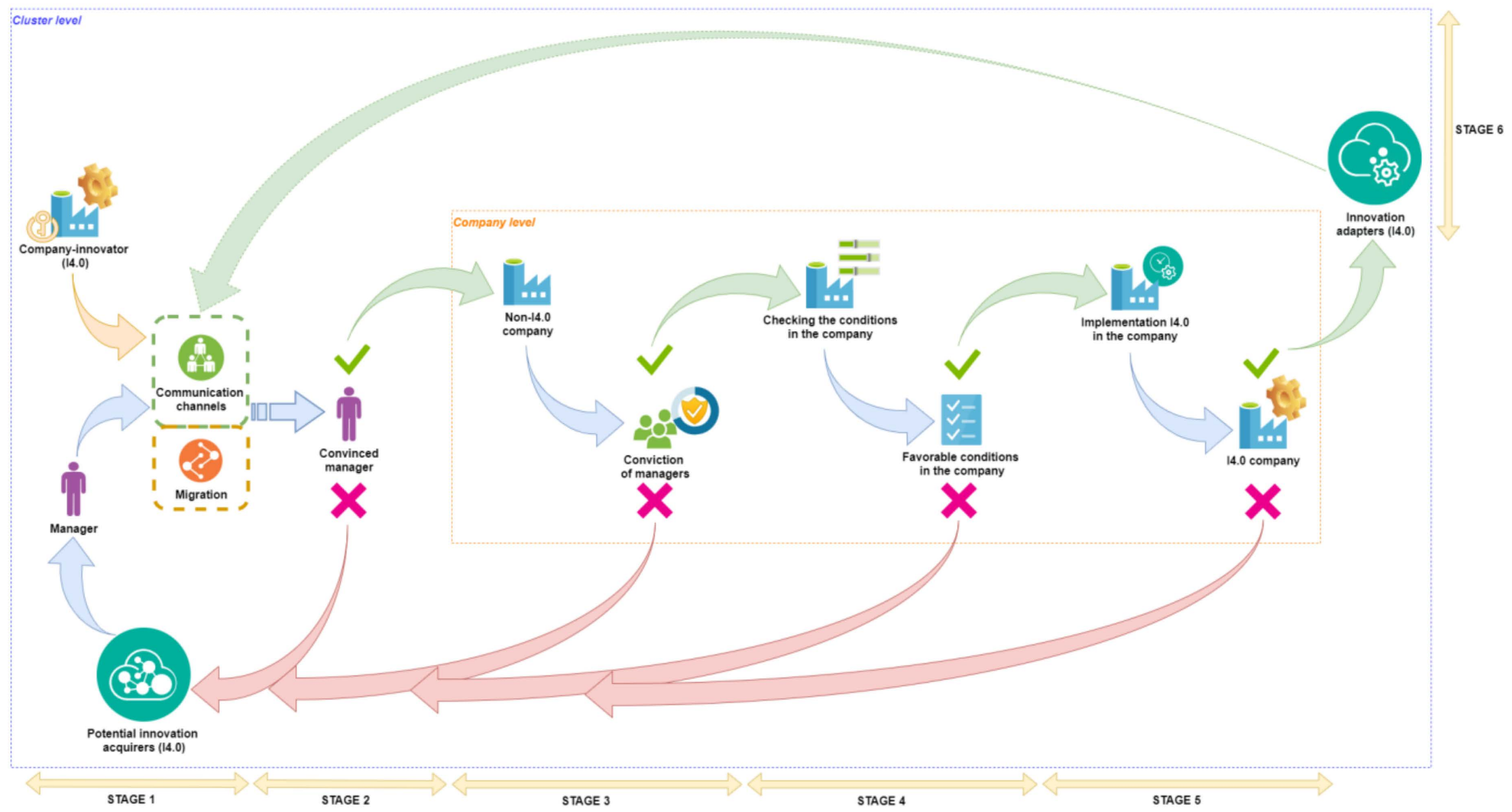

Figure 4. Model of diffusion of Industry 4.0 in the Marshallian cluster (in the paper, "non-I4.0 company" is a company which does not implement Industry 4.0 solutions, while "I4.0 company" is a company implementing Industry 4.0 and striving for increased innovativeness). 
Industry 4.0. research has shown that managers usually learn about the concept themselves. Acquiring and supplementing such knowledge can be a time-consuming process and often has no practical impact on the reality of the company. When analyzing the potential inherent in the cluster, it should be noted that it should be used to the maximum extent in favor of its members. For this reason, the developed model distinguishes two main communication channels existing in the cluster, thanks to which the manager can learn about innovation:

- during meetings dedicated to Industry 4.0 organized by the cluster coordinator;

- by communication in word-of-mouth conversations between managers of cluster enterprises.

The first of the abovementioned communication channels is dedicated meetings within the cluster. The cluster coordinator plays a key role in the development of the cluster. They support cluster entities in mutual cooperation and promote the implementation of innovative solutions implemented in the cluster. Staying in close contact with cluster members, the cluster coordinator is a communication node through which information on development needs and identification of appropriate solutions are transmitted [34]. In the context of Industry 4.0 diffusion, one of the main tasks of a cluster coordinator should be the organization of dedicated workshops and training sessions devoted to Industry 4.0.

A particularly important role of the coordinator is at the initial stage of diffusion of innovation, when the cluster members become familiar with the concept and start mutual cooperation in a given area.

Research results [35] indicate that when implementing new solutions, companies most often reach for knowledge to their business partners who practice the concept, and that one of the main reasons for abandoning its implementation is the lack of a good example. The more examples are shown during meetings in a cluster, the more convinced managers will be by a given concept and the greater the chance for absorption of innovation by other cluster entities. The coordinator's tasks include building an atmosphere of trust among cluster members, as well as stressing the need to implement Industry 4.0 solutions in cluster enterprises that will help them eliminate or at least reduce unnecessary resources (and therefore costs), improve processes, and respond to customer needs faster. It also follows from the above that the coordinator himself should be fully aware and convinced of the legitimacy of actions taken towards Industry 4.0.

The second featured communication channel that allows managers to learn about Industry 4.0 is "word-of-mouth". Managers belonging to one cluster often communicate with each other, as well as meet at various types of ventures (e.g., fairs, presentations of new products, thematic exhibitions, and other events), where they have the opportunity to exchange their experiences, as well as share a specific type of knowledge. It should be noted that the exchange of information through this channel (as well as in the case of the first channel discussed) can occur when a culture of knowledge sharing exists in the cluster, which can be crucial for its development. Therefore, managers of cluster enterprises should identify with the cluster's membership and be interested in its expansion so that such exchange can take place. Managers from traditional culture organizations may have a problem sharing knowledge or learning without seeing the need for change. In this way, they close themselves to innovation. Nevertheless, the cluster is an entity that exists in an environment of constant change and high competition, which prompts the enterprises that make it up to move towards changes adapted to the requirements of the environment.

Creating a culture of knowledge sharing in a cluster is not a quick or easy process. At this point, one should also emphasize the unimpaired role of the coordinator, who should make partners in the cluster realize that they are working for the common good-achieving a highly competitive position on the market, as well as in line with the creation of greater than before profits due to improving the quality of products and services, and improving organization of work and shortening the duration of implemented processes.

Comparing the above two communication channels, it should be clearly stated that meetings dedicated to Industry 4.0 organized by the cluster coordinator are a stronger and more convincing 
channel for action. Thanks to this, managers can become more convinced about the necessity of implementing solutions in their companies.

\subsection{Stage 2: Conviction of the Need to Implement Industry 4.0}

This is a stage verifying the manager's attitude to acquired knowledge. The new knowledge received regarding the Industry 4.0 concept can be obtained by the manager:

- accepted as useful - the manager understands the main assumptions and premises of the concept, sees the benefits achievable thanks to its implementation in the company environment;

- rejected as useless-the manager perceives the concept as unsuitable in the realities of their own company due to misunderstanding the concept or near-sightedness.

Realizing that Industry 4.0 can lead to a more effective use of the potential inherent in the company, a manager who will consider newly acquired knowledge as useful will strive to expand this knowledge by reaching for various sources of information. However, according to the results of the research [35], they will most often reach for the knowledge of business partners in the cluster implementing innovative solutions. The knowledge acquired and verified by examples of partners should confirm the manager's belief that it is necessary to implement a given concept in an enterprise. However, managers from various enterprises with a diversified culture and different attitudes will be convinced by it at different times. Some of them will need more examples or more cluster enterprises involved in Industry 4.0 to get on the road. Also, according to the diffusion curve, managers initially rejecting the idea of Industry 4.0 by observing the commitment to the improvement activities of an increasing number of enterprises, as well as using examples of partner companies, will also likely see the need to improve processes in their own company.

\subsection{Stage 3: Initial Verification of the Cluster Enterprise's Preparation for the Implementation of Industry 4.0}

Stage 3 is the first step to Industry 4.0 implementation. Believing that Industry 4.0 is an added value for the company, the manager should be ready to take on the challenges related to it. Management is the main engine of change in a company, when in a micro or small company one manager with high motivation and willingness to introduce changes may be enough to initiate the implementation of innovation, in the case of large- and medium-sized companies, where the number of managers is definitely higher, one person most likely will have little chance of achieving them. Considering the above, it is recommended to have about $3 / 4$ managers convinced of the need to implement changes to start implementing innovations in the enterprise. Lack of such belief will be tantamount to not preparing the company to implement Industry 4.0, as well as a lack of sense in undertaking improvement actions, which without proper belief and support of the management will be doomed to failure.

\subsection{Stage 4: Checking the Conditions for Implementing Industry 4.0 in the Selected Enterprise}

This stage is the next step towards Industry 4.0 and aims to verify the actual state of preparation of the enterprise for implementation. Each enterprise is an individual unit with its own culture, attitude to changes, and innovative solutions, having specific values, principles and norms. Despite the same main goal - to generate the highest possible profit—-the way to achieve it for each separate organizational unit is different. One company can boast a close-knit and committed team of employees, others-openness to changes, another-efficient communication channels within the organization.

To find out the main factors that are decisive in the context of the implementation of Industry 4.0 in the enterprise, the CATI and CAWI surveys were conducted among enterprises of Marshallian clusters, which resulted in 173 responses. The survey allowed the selection of five main factors. They were (presented by hierarchical importance):

(1) commitment of management and managers;

(2) employee involvement; 
(3) well-prepared implementation plan;

(4) consistency in taking action;

(5) company culture.

The varied configuration of these factors can answer the question of whether the selected cluster enterprise is ready to implement the discussed concept or not. A favorable configuration of factors will indicate the existence of a favorable environment in the company in favor of implementing Industry 4.0. Unfavorable configuration of the main factors will indicate that the company is not yet prepared for the implementation of the concept and must acquire a broader knowledge and insight on a given topic.

The above two stages constitute a two-step verification of the company's preparation for the implementation of Industry 4.0. Successful passage through them is a positive signal for successful implementation in the enterprise.

\subsection{Stage 5: Implementation of the Industry 4.0 Concept in a Cluster Enterprise}

This stage is responsible for the proper implementation of the Industry 4.0 concept in the cluster unit. Undertaking specific slimming activities at this stage shows nothing else but the absorption of innovation. The cluster enterprise assimilates innovation at the right time, relying on both the knowledge and experience of partner companies in the cluster, as well as their own knowledge acquired during preparations for the implementation of Industry 4.0.

Regular meetings of enterprises within the cluster will also allow for verification and consultation of actions taken, which will ensure that companies implementing Industry 4.0 solutions are aware of receiving support in implementation and minimizing the risk of error. Nevertheless, improper treatment of Industry 4.0 principles, or an incorrect understanding of specific solutions, may lead to unused potential inherent in the company (favorable conditions for implementation) as well as in the cluster (support of partner companies) and result in failure to implement innovative solutions.

\subsection{Stage 6: Diffusion of Innovation in the Form of Industry 4.0 Solutions in the Marshallian Cluster}

The last highlighted stage deals with the spread of innovation among subsequent cluster members who are in the group of potential buyers. An enterprise that has followed the example of innovators and absorbed this concept can become an example for other companies that are potential buyers of innovation in the Marshallian cluster. The company's experience in the implementation of selected tools, emerging problems, ways of solving them, gaining wider knowledge, signaling the results obtained, as well as demonstrating the desire to continue and expand improvement activities in further areas in the enterprise, can become not only a valuable source of information for subsequent followers, but also a stimulus to the activities of Industry 4.0 for companies that, due to fears or disbelief, have not yet taken these actions. However, not every company may be willing to set an example to other companies in the cluster. At this time, the coordinator plays an important role, whose task is to build trust and create an atmosphere of cooperation among members of the Marshallian cluster in accordance with achieving synergistic effects.

According to the innovation diffusion curve, due to the increasing number of innovators over time, managers who initially rejected knowledge of Industry 4.0 or did not reinforce their belief that it is necessary in the realities of their company will become increasingly convinced of it. According to the above, the first process of the presented algorithm takes into account both the acquisition and expansion of knowledge about innovation in the cluster.

It can also be seen that the discussed model, in addition to diffusion of innovation, also applies to the absorption of Industry 4.0 by cluster enterprises. As mentioned above, the process of diffusion of innovation is inseparable from knowledge transfer and absorption. Therefore, absorption cannot be omitted in the developed model, because without the successful application of innovation one cannot speak of its diffusion. In addition, the model assumes that there is at least one enterprise in the 
cluster that effectively uses Industry 4.0 solutions and can be an example, as well as a desire to share knowledge with other cluster members.

Considering the fact that the diffusion of innovation in the Marshallian cluster is being considered, its characteristic aspect should be taken into account, namely the migration of employees within cluster enterprises. Then, another possible communication channel appears, thanks to which knowledge about the concept under consideration can be transferred. Thus, four possible cases of manager migration in a cluster can be distinguished (Figure 5):

1. migration of an I4.0 manager to a non-I4.0 company (in this paper, "non-I4.0 manager" is a manager not convinced of the necessity to implement Industry 4.0, while "I4.0 manager" is a manager convinced of the necessity of Industry 4.0 implementation);

2. migration of an I4.0 manager to an I4.0 company;

3. migration of a non-I4.0 manager to a non-I4.0 company;

4. migration of a non-I4.0 manager to a I4.0 company.

(a)

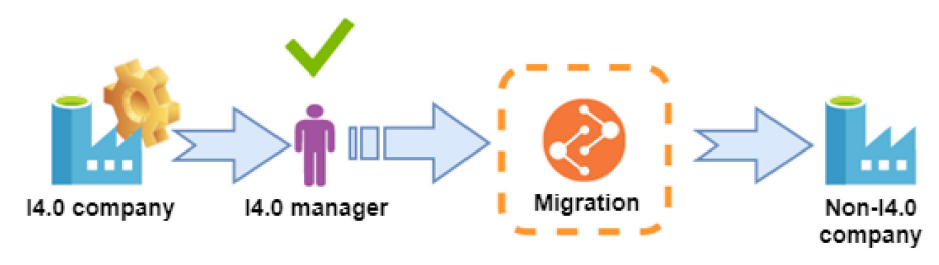

(b)

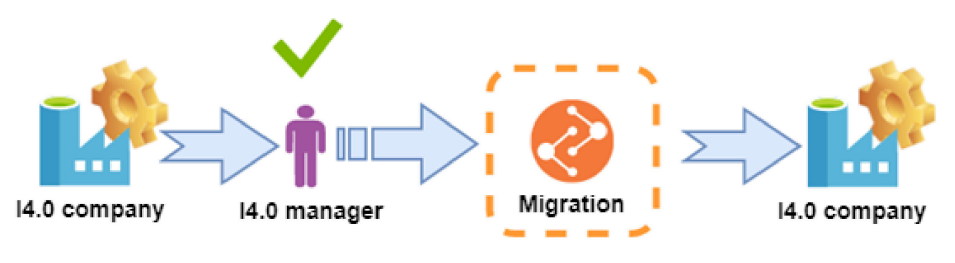

(c)

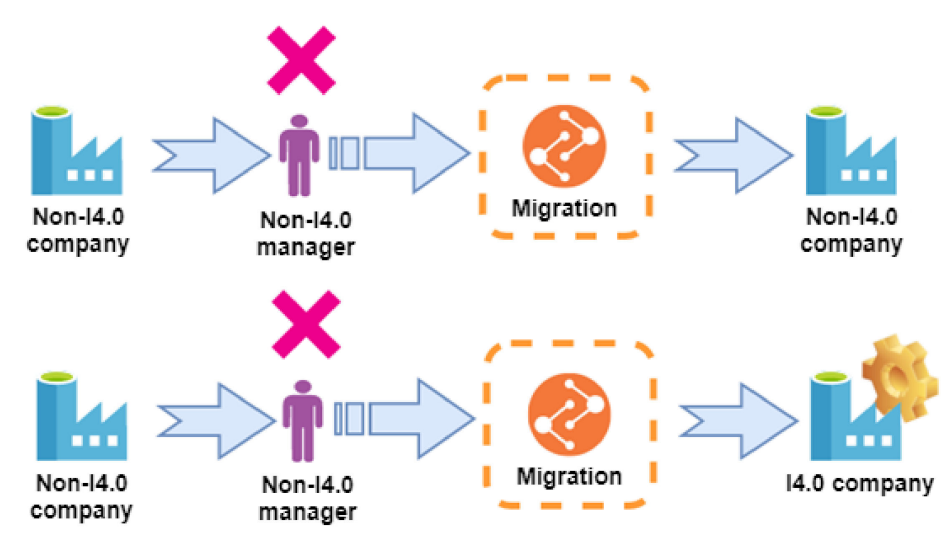

Figure 5. Migration options: (a) manager I4.0 $\rightarrow$ company non-I4.0; (b) manager I4.0 $\rightarrow$ company I4.0; (c) manager non-I4.0 $\rightarrow$ company non-I4.0; (d) manager non-I4.0 $\rightarrow$ company I4.0.

The first migration case-I4.0 manager to non-I4.0 company-is an example of transferring knowledge and experience of a manager from another company practicing Industry 4.0 to a company that does not take such actions. The manager's conviction of the legitimacy of Industry 4.0 actions, supported by their own observation and practical examples, can initiate implementation or at least arouse interest in the concept among other members of a non-I4.0 company.

The second migration case signals the transfer of a manager's knowledge to a company already implementing Industry 4.0. In this case, the new manager can strengthen the implementation of slimming activities in a new company with their knowledge and experience. The next, third case presents the manager's transition without conviction about a given concept to a non-I4.0 company, which in turn does not assume any changes to the last one towards the Industry 4.0 concept. The last, 
fourth case shows the manager's transition without conviction to the company implementing Industry 4.0. In this case, the manager will also not be a link strengthening Industry 4.0 activities in the new company, but has favorable conditions to acquire such belief.

The modeled process of diffusion of innovation in Marshallian clusters shows the main steps in spreading knowledge about Industry 4.0 among cluster enterprises. The consequence of following them and meeting the conditions contained therein will be an effective and quick diffusion of innovation in the cluster. The presented model indicates points that are critical in the process of diffusion and whose omission may result in its failure or extension in time. In addition, it gives the cluster coordinator the opportunity to follow the trends of cluster development towards innovation. The model also-thanks to the exchange of knowledge about Industry 4.0, and thus having a common interest-can give grounds for closer ties and deepen cooperation between cluster members. The main premise of the model is the involvement of as many cluster enterprises as possible in the shortest possible time in innovative activities, in line with the creation of the so-called "Industry 4.0 cluster", i.e., a cluster in which enterprises are focused on innovation.

\section{Validation of the Model}

To verify the hypotheses, the presented model was implemented in an IT environment-more precisely, in the software Code: Blocks.

In the subject study a 36-member cluster was adopted for model verification. Due to the distribution of responses obtained in the survey, the number of individual enterprises was (the research assumed the size of the average statistical Marshallian cluster in Poland): 4 large, 14 medium, 12 small, and 6 micro. Considering the average number of employees in each enterprise, as well as the fact that the managerial staff in production enterprises constitute no more than $10 \%$ of all employees of the company [36], the number of managers who were to be analyzed in the simulation was calculated (Table 2).

Table 2. Number of managers in the simulation model.

\begin{tabular}{cccccc}
\hline Size of a Company & Micro & Small & Medium & Large & Total \\
\hline Number of companies in a cluster & 6 & 12 & 14 & 4 & 36 \\
Average number of employees & 5 & 30 & 150 & 625 & \\
Number of managers in a company (10\%) & 1 & 3 & 15 & 63 & \\
Number of managers in a cluster & 6 & 36 & 210 & 252 & 504 \\
\hline
\end{tabular}

The simulation assumed that in the Marshallian cluster there is always one company that implements the selected Industry 4.0 solution. Thus, the innovator enterprise from which knowledge will spread may be a micro-enterprise, small enterprise, medium, or large. It was also assumed that in an enterprise that is an innovator, $100 \%$ of managers are convinced of the need to implement the analyzed concept. Table 3 therefore shows the number of managers-innovators and the number of managers who are potential buyers for each of the simulation variants.

Table 3. Options in the simulation model.

\begin{tabular}{ccc}
\hline Variants & Innovator & Innovation Acquirers \\
\hline Option 1 & 1 & 503 \\
Option 2 & 3 & 501 \\
Option 3 & 15 & 489 \\
Option 4 & 63 & 441 \\
\hline
\end{tabular}

It should be noted that the strength of the influence of managers from a certain size of cluster enterprises is not identical. While large enterprises are often an example to follow and have a much greater impact (than, e.g., a micro or small enterprise) on other entities, it was decided to 
assume in the model that the influence of managers increases with the increase in the size of the enterprise from which they come: manager from micro enterprise-influence 1; manager from small enterprise-influence 2; manager from medium enterprise-influence 4; manager from large enterprise-influence 8 . The relationships between enterprises in the cluster are presented in the graph shown in Figure 6 (due to the significant number of connections between enterprises, the Marshallian cluster in Figure 6 has been reduced twice (18 companies proportionally) in relation to the cluster actually analyzed). In addition to the influence of enterprises on other enterprises, the influence of the enterprise on itself is shown (marked with a black arrow). Impact is about interactions within the unit-in other words, contact between managers of a given company.

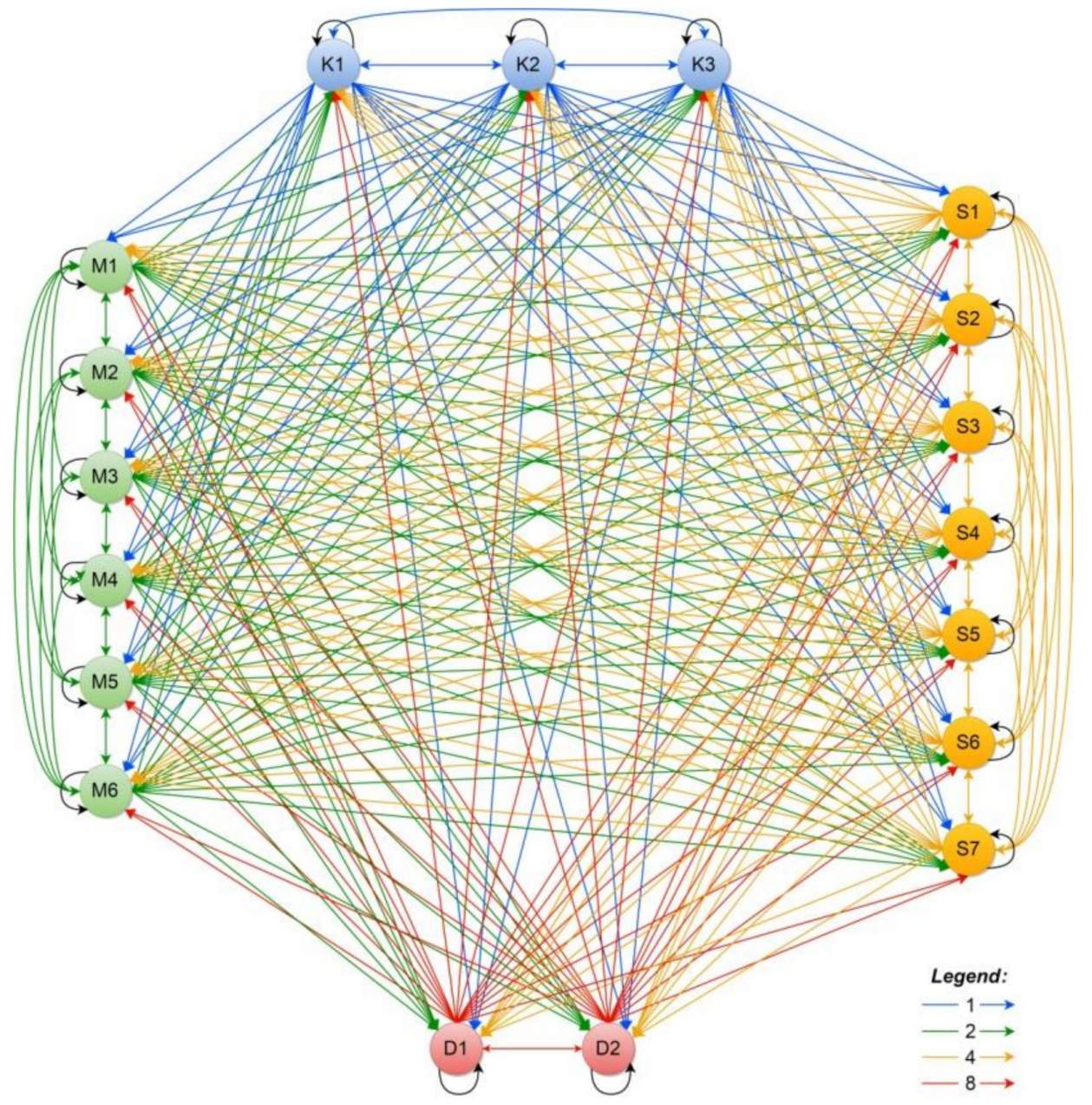

Figure 6. Analyzed Marshallian cluster structure (D-large company; S-medium-sized company; $\mathrm{M}$-small company; and $\mathrm{K}$-micro-company ).

In Figure 6, in addition to the influence of enterprises on other enterprises, there is the influence of the enterprise on itself (marked with a black arrow). The influence emerges from interactions within the unit, in other words - contact between managers of a given company.

All managers in the Marshallian cluster can have three states of knowledge about Industry 4.0: 0 - the manager has no knowledge of I4.0; 2-the manager has knowledge of I4.0, but is not convinced of the correctness of its use in practice; 4-the manager is convinced of the need to implement I.40 in the organization.

The model presents three communication channels, thanks to which the management can gain knowledge about Industry 4.0. These channels will be treated in the model as dynamic variables dependent on constants affecting them (Table 4). 
Table 4. Variables and constants in innovation diffusion process.

\begin{tabular}{cc}
\hline Variables & Constants Affecting Variables \\
\hline Meetings dedicated to Industry 4.0 & $\begin{array}{c}\text { 1. Number of meetings } \\
\text { 2. Effectiveness of an example }\end{array}$ \\
\hline Word-of-mouth & $\begin{array}{c}\text { 1. Frequency of contact } \\
\text { 2. Strength of impact }\end{array}$ \\
\hline Migrations & 1. Frequency of migration \\
\hline
\end{tabular}

The dynamic variable "Meetings dedicated to Industry 4.0 " is influenced by two constants, for which explanations are given below:

- number of dedicated meetings-this is the number of meetings dedicated to Industry 4.0 topics organized by the cluster coordinator over the year during which the innovator enterprise can share knowledge with managers of other cluster companies. The number of meetings adopted in the model is one time in two months, and the number of participants in such a meeting is: from a micro-company—one person; from a small company—one person; from a medium company—two people; from a large company-three people;

- effectiveness of the example-refers to the impact (strength of the example) of the enterprise from which the manager comes. In this case, the ratio: impact (manager $\mathrm{D}|\mathrm{S}| \mathrm{M} \mid \mathrm{K}$ ) / impact (manager $\mathrm{D}|\mathrm{S}| \mathrm{M} \mid \mathrm{K}$ ) is taken into account. Depending on the size of the innovator's company, the following dependencies occur:

- innovator: big company (D)—the effectiveness of the example can be: $8 / 8 ; 8 / 4 ; 8 / 2 ; 8 / 1$. This means that the effectiveness of the example is always unconditionally accepted. The influence of a manager from company $D$ on other managers is always certain $(p=1)$;

- innovator: medium-sized company (S) — the effectiveness of the example can be: $4 / 8 ; 4 / 4 ; 4 / 2$; $4 / 1$. This means that only in the first case is there a $50 \%$ chance $(p=1 / 2)$ that the manager from company $S$ will convince the manager from company $D$, in other cases there is certainty of the manager's influence on managers of other companies $(\mathrm{p}=1)$;

- innovator: small company $(\mathrm{M})$ - the effectiveness of the example can be: $2 / 8 ; 2 / 4 ; 2 / 2 ; 2 / 1$, this means that there is a $25 \%$ chance $(\mathrm{p}=1 / 4)$ that a manager from company $\mathrm{M}$ will convince a manager from company $\mathrm{D}$ and $50 \%$ chance $(\mathrm{p}=1 / 2)$ that a manager from company $\mathrm{M}$ will convince a manager from $S$. In other cases, there is certainty about belief $(p=1)$;

- innovator: micro-company $(\mathrm{K})$ — the effectiveness of the example can be: $1 / 8 ; 1 / 4 ; 01.02 ; 1 / 1$. This means that there is about a $13 \%$ chance $(\mathrm{p}=1 / 8)$ that a manager from company $\mathrm{K}$ will convince a manager from company $\mathrm{D}, 25 \%$ chance $(\mathrm{p}=1 / 4)$ that a manager from company $K$ will convince a manager from company $S$ and $50 \%$ chance $(p=1 / 2)$ that a manager from company $\mathrm{K}$ will convince a manager from company $\mathrm{M}$. In cases of influencing a manager from a micro-company, the effect is certain $(p=1)$.

The dynamic "word-of-mouth" variable is influenced by two explanation constants, which are as follows:

- frequency of contacts-this is the number of managers with whom the selected manager will meet in the cluster during the year. These contacts could be external, i.e., the number of meetings with managers of other companies in the cluster (the model adopted 10 meetings for 1 manager per year) and internal, i.e., the number of meetings with managers of the company in which the manager currently works (in the model 20 meetings for 1 manager per year);

- $\quad$ strength of impact-refers to the level of knowledge about Industry 4.0 possessed by the manager $(4,2$, or 0$)$. Knowledge flows from people with knowledge and conviction to people without knowledge and unconvinced. 
The dynamic variable "Migrations" depends on one constant, namely:

- migration frequency-this is the number of managers migrating within the cluster per year. The number of manager migrations per year assumed in the model is 10\% (the Labor Market Monitor implemented by the Randstad Research Institute indicates that the change in the workplace of middle management is $12 \%$, while for the higher level— $8 \%$ [37]).

Concerning contacts of managers, an important aspect resulting from the conducted research should be emphasized-the number of managers signaling the exchange of knowledge in the cluster is about $31 \%$. Therefore, it has been assumed in the model that only every third interaction of managers will result in the flow and exchange of knowledge between them. In addition, in the case of meetings dedicated to Industry 4.0, the efficiency of the example plays a key role (i.e., the company impact parameter: $8,4,2$, or 1 ), the role of conviction (the parameter of knowledge possessed by the manager: 4,2 , or 0 ) plays a secondary role. During Industry 4.0 meetings the speaker's qualifications are an obvious attribute (a manager should have knowledge if they are an example for other managers), so it becomes an important aspect of the size of the company from which he comes. On the other hand, in the case of word-of-mouth meetings (i.e., external and internal meetings), strength of persuasion is of paramount importance, in other words-the manager's individual knowledge, and not their origin from the company D or M. In this case, the size of the company from which the manager comes is a complementary factor.

Stage 4 of the proposed model involves checking the conditions in the enterprise in terms of the possibility of successful implementation of solutions within Industry 4.0. As a result of research, five most important conditions have been identified that affect the successful implementation of the concept (commitment of management and managers; employee involvement; well-prepared implementation plan; consistency in taking action; company culture).

Each of the conditions was given a weight from 5 to 1, where: 1-very important condition (weight 5); 5-least important condition (weight 1). In addition to the specified weight, each condition had five possible ratings (5-condition fully met; 1 -failure to meet the condition). In the simulation model, the assessment of conditions for individual enterprises was selected randomly. The product of the balance with the determined condition assessment shaped the weighted value. It was assumed that if the weighted average of the five main factors in the enterprise is greater than or equal to 3-the enterprise has favorable conditions for implementation. If this value is below 3-the enterprise is doomed to failure in implementation

In the simulation model, in addition to the managers' knowledge, the states of the enterprise were separated. The adopted relationships between them are presented in Table 5.

To sum up, additional assumptions adopted for model verification should be presented:

- the Marshallian cluster was treated as a source of obtaining information of innovation;

- the number of enterprises of a certain size in the Marshallian cluster was constant;

- the number of managers in the Marshallian cluster was constant;

- a manager from a micro-enterprise cannot migrate to other enterprises because they are the founder of the company;

- $\quad$ an enterprise-innovator has $100 \%$ of managers convinced of the need to implement Industry 4.0 (everyone has a knowledge of 4) and is open to sharing knowledge with business partners in the Marshallian cluster (the company has a status of 5);

- a cluster enterprise that has started implementing selected Industry 4.0 solutions (implementation in the context of the proposed model is understood as the successful implementation of the selected Industry 4.0 tool and further continuation of efforts to increase the company's innovation) will continue to implement innovative solutions (in other words, it may not withdraw from further implementation). 
Table 5. Interdependencies between managers and companies in clusters.

\begin{tabular}{|c|c|}
\hline $\begin{array}{l}\text { Assumptions and Characteristics of Managers } \\
\text { (IF) }\end{array}$ & $\begin{array}{l}\text { Characteristics of Companies in the Marshallian Cluster } \\
\text { (THAN) }\end{array}$ \\
\hline 0 & 0 \\
\hline Managers do not know about Industry 4.0 & Lack of knowledge on I4.0 \\
\hline $\begin{array}{l}0,2 \text { and } 4 \text { while } \sum 2+4 \geq 50 \% \text { managers of the company } \\
\text { Some managers do not know about I4.0-0, some } \\
\text { managers know about I4.0 but are not convinced to } \\
\text { implement it-2, some managers are convinced about } \\
\text { I4.0 implementation- } 4 \text {. }\end{array}$ & $\begin{array}{c}1 \\
\text { Growing interest on I4.0 in companies in the Marshallian } \\
\text { cluster }\end{array}$ \\
\hline $\begin{array}{c}\sum 4 \geq 70 \% \text { of managers of a company } \\
\text { At least } 70 \% \text { of managers is convinced about } \\
\text { I4.0 implementation }\end{array}$ & $\begin{array}{c}2 \\
\text { Preliminary decision on I4.0 implementation }\end{array}$ \\
\hline $\begin{array}{l}\text { Checking main determinants of decision in } \\
\text { I4.0 implementation. } \\
\text { Weighted average from five conditions } \geq 3\end{array}$ & $\begin{array}{c}3 \\
\text { Company has conditions supporting I4.0 implementation }\end{array}$ \\
\hline Initiating implementation of I4.0 & $\begin{array}{c}4 \\
\text { Company launched I4.0 implementation }\end{array}$ \\
\hline Commitment to and continuation of I4.0 implementation & $\begin{array}{c}5 \\
\text { Company is committed to I4.0 implementation }\end{array}$ \\
\hline
\end{tabular}

In connection with the assumptions of the model, optimization of the target in the Marshallian cluster occurs when the diffusion time of innovation tends to a minimum (is as short as possible) and the sum of the states of cluster enterprises tends to the maximum (accumulation of the highest possible states - in the analyzed case $5 \times 36=180)$, that is, when the cluster vector is described by $[5,5,5, \ldots . .5]$ (Formula (1)):

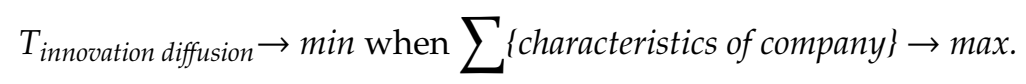

The above-mentioned assumptions, as well as formulated criteria and conditions adopted in the model, allowed the creation of the basis for its implementation in an IT computer system.

Code: Blocks was used to prepare the simulation algorithm and perform calculations. It is a free software used to run applications in $\mathrm{C}++$ language offering the latest compilers. The main advantage of Code: Blocks is total independence from the operating system; hence, the code is fully portable and can be finally run on machines with high computing power.

The simulation was based on a basic loop that generated the cluster state in the next steps. Each step symbolized a set time interval (e.g., day) of evolution of the studied cluster. The state of the cluster was the sum of the states of individual enterprises. The basis for calculating the subsequent statuses of enterprises that are participants of the cluster was information about managers and conditions necessary for the implementation of Industry 4.0. The state of knowledge of managers about Industry 4.0 was updated at every step, through randomly generated contacts between them or migrations between enterprises. External contacts of managers with other representatives of the Marshallian cluster companies, contacts of managers within the company, as well as their migrations are called "association" in the program. Each event in the simulation was analyzed in detail so that it reflected the real possibilities of transferring knowledge. Acquiring or expanding knowledge about Industry 4.0 by a manager affects the change of their knowledge. Changing the knowledge of managers directly affects the assessment of the state of the enterprise and, as a consequence, the state of knowledge of the entire cluster.

Due to the above, the simulation in each step was based on a random set of events, which means that the obtained results are of a stochastic nature (cluster states form the Markov chain (Markov chain is the complete system of random events (states) E1....En, in which it is assumed that the probability $\mathrm{pn}(\mathrm{t})$ that the event $\mathrm{E} 1$ will occur in the experiment (moment) provided that the experiment (moment) $\mathrm{t}-1$ event $\mathrm{E} 1$ occurred, it does not depend on what events occurred in previous experiments 
(moments) [38]). Observation of many simulations made it possible to set common trends that provide the basis for defining the rules describing the diffusion of innovation in the context of Industry 4.0 in specific initial conditions.

In order to verify the research hypotheses, a number of simulations were carried out with differentiated input data:

- the course of innovation diffusion depending on the size of the innovator;

- the course of diffusion of innovation depending on the number willing to share knowledge;

- the course of diffusion of innovation depending on the number of migrants;

- the course of diffusion of innovations depending on the number of meetings dedicated to innovations;

- the course of diffusion of innovations depending on the number of innovators.

The main purpose of the simulation was to observe and analyze changes in the status of Marshallian cluster enterprises, i.e., diffusion of innovation, over time.

\section{Discussion}

Model validation by means of simulations carried out resulted in formulating the following conclusions:

1. There is a number of factors that determine the rate of diffusion of innovation in the Marshallian cluster. Such factors include the willingness to share knowledge, the level of migration in the cluster, the number of meetings devoted to Industry 4.0 initiated by the cluster coordinator, the number and size of innovators in the cluster structure. Diffusion takes or slows down depending on the configuration of the factors mentioned.

2. The results of the simulation showed that the larger the innovator company, the faster the moment of spreading knowledge about innovation (Industry 4.0) in the cluster. The smaller the enterprise promoting knowledge of Industry 4.0, the more time it takes for the cluster to "mature" to start diffusing in it (in the case of a micro-company, this time reaches over three years). Due to the structure of Marshallian clusters, which consists mainly of enterprises belonging to the SME sector, it is recommended to start diffusion from a medium-sized enterprise, because compared to a large innovator company it requires the shortest period of "maturation" of the cluster for diffusion.

3. Despite the fact that the size of the subject-innovator affects the moment of diffusion beginning in the cluster, it does not affect diffusion within individual organizational units. Simulations have shown that the estimated transition time from the beginning of diffusion in the cluster to reach $80 \%$ of enterprises involved in Industry 4.0 (with standard settings) is almost identical in each case.

4. Encouraging cluster managers to share knowledge is conducive to accelerating the pace of innovation diffusion. Simulations have shown that the higher the level of knowledge sharing in a cluster, the faster the knowledge is spread (reducing diffusion time by up to $20 \%$ ).

5. Increasing the level of migration of managers in the cluster shortens the time of spreading knowledge about Industry 4.0, however, it extends the time of diffusion in individual enterprises. The higher the number of migrants in the cluster, the faster knowledge is disseminated between enterprises.

6. Simulations have shown that increasing the number of small-scale innovators does not significantly affect the course of diffusion. It is not recommended to initiate the diffusion of innovation from two small enterprises, or a small and medium enterprise, because it does not introduce major changes in the speed of knowledge spread in relation to a single innovator. If a decision is made to disseminate innovation from two organizational units, it is recommended to transfer knowledge to two medium-sized entities, because only then is it possible to shorten the diffusion time in the cluster. However, it should be remembered that the time of innovation transfer in one medium-sized enterprise may differ from the time of innovation transfer in another, which may also be the reason for the delay of the moment of diffusion initiation in the cluster structure. 
It should be noted that there are some limitations that the presented model has. They are:

- the model does not take into account the independent acquisition of managerial knowledge by, e.g., studies, training, independent study of literature items. The model assumes that the knowledge of a non-I4.0 manager is always acquired from an I4.0 manager. Under real conditions, non-I4.0 managers can often acquire and multiply their knowledge of innovation by itself, which in turn will promote and accelerate the diffusion of innovation;

- the model does not take into account the age of enterprises entering the Marshallian cluster-young enterprises that appeared in times of dynamic changes are more flexible and are able to notice the need to move with the times faster by implementing modern management concepts, while older enterprises are most often attached to long-standing traditions and specific procedure. This criterion may have the effect of accelerating or slowing down the diffusion of innovation over time;

- the model does not take into account the age of the Marshallian cluster-young clusters point to the need to strengthen basic functions such as building relationships and trust, management professionalization, and creating and continuous development of the cluster structure. This, in turn, may translate into a longer time for the spread of innovation compared to older clusters who have already passed this path and in which enterprises have a degree of trust in each other;

- the model does not take into account the geographical distance of cluster enterprises in relation to each other. Some cluster enterprises are grouped around one agglomeration, while others may be spread across different regions. As a result of such a dispersion of enterprises belonging to one cluster, the diffusion of innovation may slow down, as contacts as well as meetings of managers become difficult.

Nevertheless, the presented model indicates points that are critical in the process of diffusion and whose omission may result in its failure or extension in time.

\section{Conclusions}

The content presented in this paper concerned the spread of innovation, which was considered as the concept of Industry 4.0 among Marshallian cluster enterprises. It has been shown that the process of diffusion of innovation is a complex process, which is influenced by many factors. The key goal of the article was to develop a model of diffusion of innovation in Marshallian clusters. The presented considerations do not exhaust the entire spectrum of issues related to a given topic. Nevertheless, they provide the basis for drawing conclusions that allow verification of the hypothesis and answering the research question.

To answer Research Question 1, the model of Industry 4.0 knowledge diffusion in Marshallian clusters was developed and presented in the model development section. The model explains the mechanism of knowledge diffusion in Marshallian clusters environment.

To identify the factors affecting Industry 4.0 knowledge diffusion, research among companies was carried. CATI and CAWI research gave the opportunity to select the five most important factors conditioning the implementation of innovation, namely: the involvement of management and employees, a well-prepared implementation plan, consistency in undertaking actions, and the culture prevailing in the company. The results provided answer to Research Question 2.

To verify the hypothesis the simulation experiments were carried out. $\mathrm{C}++$ simulations have shown that the rate of innovation diffusion depends on the size of the enterprise cluster that promotes innovation. The results of the simulations carried out showed that the larger the enterprise-innovator, the faster the moment of diffusion of innovation in the Marshallian cluster begins. Moreover, the simulations carried out showed that many factors influence the diffusion of innovations, among them: the size of the enterprise-innovator, the number of people migrating in the cluster, the number of willing to share knowledge, the number of innovators, as well as meetings dedicated to Industry 4.0. Hence, the hypothesis was confirmed. 
This article does not exhaust all possible areas of research in the field of diffusion of innovation in Marshallian clusters, which generates the need for further research. Important research aspects are:

- analysis of the impact of the age of individual enterprises in a Marshallian cluster on the speed of dissemination of knowledge about innovation;

- studying the impact of age and maturity of the cluster structure on the rate of innovation spread;

- estimation of the actual strength of the impact of the cluster's environment on the company's ability to take over innovation;

- expanding the catalog of parameters affecting the process of diffusion of innovation in a Marshallian cluster;

- analysis of the spread of innovation (Industry 4.0) in different types of clusters and the search for common and specific relationships for each of them.

The most important conclusions from the conducted analyzes indicate that there is a need to promote knowledge of Industry 4.0 among Marshallian cluster enterprises so that they can achieve a highly competitive position on the market. It is important that the innovator in a Marshallian cluster should be a large- or medium-sized enterprise, which will significantly accelerate the moment of diffusion beginning in the cluster structure. There should be a culture of cooperation built at the cluster level and encouragement for organizations to share knowledge about innovation in line with building a competitive and being prepared for future changes of the region in the country. Moreover, cluster coordinators should work on creating conditions for learning and sharing knowledge about Industry 4.0 among representatives of the management card of units that are participants of a Marshallian cluster, as well as look for new communication channels (e.g., an intranet platform for exchanging information within the cluster).

Author Contributions: Conceptualization, I.P. and A.S.; methodology, I.P.; software, G.P.; validation, I.P.; formal analysis, J.O.-S.; investigation, J.O.-S. and A.S.; resources, A.S; data curation, M.F.; writing-original draft preparation, I.P.; writing - review and editing, A.S. and J.O.-S.; visualization, I.P.; supervision, M.F.; All authors have read and agreed to the published version of the manuscript."

Funding: This research received no external funding.

Conflicts of Interest: The authors declare no conflict of interest.

\section{References}

1. Rogers, E.M. Diffusion of Innovations, 4th ed.; Free Press: New York, NY, USA, 1995.

2. Janik, A.; Ryszko, A. Mapping the field of Industry 4.0 based on bibliometric analysis. In Proceedings of the 32nd International Business Information Management Association Conference (IBIMA)_Vision 2020: Sustainable Economic Development and Application of Innovation Management from Regional Expansion to Global Growth, Seville, Spain, 15-16 November 2018.

3. Chataway, J.; Wield, D. Industrialization, Innovation, and Development: What Does Knowledge Management Change? J. Int. Dev. 2000, 12, 803-824. [CrossRef]

4. Nelson, R.R.; Winter, S.G. In Search of Useful Theory of Innovation. Res. Policy 1977, 6, 36-76. [CrossRef]

5. Tornatzky, L.G.; Klein, K.J. Innovation Characteristics and Innovation Adoption Implementation: A Meta-Analysis of Findings. IEEE Trans. Eng. Manag. 1982, 29, 28-45. [CrossRef]

6. Rogers, E.M. Diffusion of Innovations, 3th ed.; Free Press: New York, NY, USA, 1983.

7. Papazoglou, M.E.; Spanos, Y.E. Bridging distant technological domains: A longitudinal study of the determinants of breadth of innovation diffusion. Res. Policy 2018, 47, 1713-1728. [CrossRef]

8. Hult, G.T.M.; Ketchen, D.J.; Slater, S.F. Information processing, knowledge development and strategic supply chain performance. Acad. Manag. J. 2004, 47, 241-253.

9. Cantamessa, M.; Montagna, M.; Cascini, G. Design for innovation-A methodology to engineer the innovation diffusion into the development process. Comput. Ind. 2016, 75, 46-57. [CrossRef] 
10. Bergman, J.; Jantunen, A.; Saksa, J.M.; Lehtonen, M. Creating future capabilities: Scenario process in inter-industrial knowledge networks. Int. J. Manag. Concepts Philos. 2005, 1, 198-214. [CrossRef]

11. Tóth, J.; Rizzo, G. Search Strategies in Innovation Networks: The Case of the Hungarian Food Industry. Sustainability 2020, 12, 1752. [CrossRef]

12. Hodgson, G.M. Capitalism, Complexity and Inequality. J. Econ. Issues 2003, 37, 471-478. [CrossRef]

13. Morgulis-Yakushev, S.; Sölvell, Ö. Enhancing dynamism in clusters. Compet. Rev. Int. Bus. J. 2017, $27,98-112$. [CrossRef]

14. Rothwell, R. Towards the fifth-generation innovation process. Int. Mark. Rev. 1994, 11, 7-31. [CrossRef]

15. Smid, G.; Bijlsma-Frankema, K.; Derksen, H.; Bernaert, G. E-Innovation and trust Dynamics. Strateg. Chang. 2005, 14, 93-106. [CrossRef]

16. O'Regan, N.; Ghobadian, A.; Sims, M. Fast tracking innovation in manufacturing SMEs. Technovation 2006, 26, 251-261. [CrossRef]

17. Smith, M.; Busi, M.; Ball, P.; Van der Meer, R. Factors Influencing an Organisations ability to Manage Innovation: A Structured Literature Review and Conceptual Model. Int. J. Innov. Manag. 2008, 12, 655-676. [CrossRef]

18. Batz, A.; Kunath, M.; Winkler, H. Discrepancies between Cluster Services and SMEs' Needs Constraining the Creation of a Culture of Innovation Amidst Industry 4.0. LogForum. 2018, 14, 387-405. [CrossRef]

19. Nonaka, I. The knowledge-creating company. Harv. Bus. Rev. 1991, 69, 96-104.

20. Penrose, E.T. The Theory of the Growth of the Firm; Oxford University Press: Oxford, UK, 1959.

21. Borgatti, S.P.; Everett, M.G.; Johnson, J.C. Analyzing Social Networks; SAGE Publications Limited: London, UK, 2013.

22. Sternberg, R. Innovation networks and regional development-Evidence from the European Regional Innovation Survey (ERIS): Theoretical concepts, methodological approach, empirical basis and introduction to the theme issue. Eur. Plan. Stud. 2000, 8, 389-407. [CrossRef]

23. Morone, P.; Sisto, R.; Taylor, R. Knowledge diffusion and geographical proximity: A multi-relational networks approach. Open Agric. 2019, 4, 129-138. [CrossRef]

24. Wilson, K.; Doz, Y.L. Agile innovation: A footprint balancing distance and immersion. Calif. Manag. Rev. 2011, 53, 6-26. [CrossRef]

25. Similä, J.; Järvilehto, M.; Kuvaja, P. Open Innovation and Agile Development from a Process Perspective. In Proceedings of the the XIX ISPIM Conference, Loire Valley, France, 15-18 June 2008.

26. Porter, M. The economic performance of regions. Reg. Stud. 2003, 37, 545-546. [CrossRef]

27. Lin, Y.C.; Chen, W.H.; Liu, W.C.; Lin, C.F. Determinants of Micro-Enterprise Cluster Innovation: Analysis of Member Identification and Satisfaction of Leadership. Int. J. Trade Econ. Financ. 2019, 10, 30-35. [CrossRef]

28. Pawłyszyn, I.; Wyrwicka, M. Analysis of cluster enterprises from the point of view of Lean Management concept application. Visn. Nac. Univ. L'viv. Polit. 2016, 848, 37-49.

29. OECD. Enhancing the Contributions of SMEs in a Global and Digitalised Economy. 2017. Available online: https://www.oecd.org/industry/C-MIN-2017-8-EN.pdf (accessed on 2 March 2020).

30. Laudante, E. Industry 4.0, Innovation and Design. A new approach for ergonomic analysis in manufacturing system. Des. J. 2017, 20, S2724-S2734. [CrossRef]

31. Jabłoński, M. Kompetencje menedżerów w organizacji uczącej się (eng. Competences of managers in a learning organization). Zesz. Nauk. 2008, 775, 81-82.

32. Bass, F.M. A New Product Growth Model for Consumer Durables. Manag. Sci. 1969, 15, 215-227. [CrossRef]

33. Mahajan, V.; Peterson, R.A. Models for Innovation Diffusion; Sage Publications: Beverly Hills, CA, USA, 1985.

34. Christensen, T.A.; Lämmer-Gamp, T.; Meier zu Köcker, G. Perfect Cluster Policy and Cluster Program: The Cluster League-Some Food for Thought. 2012. Available online: http://regx.dk/fileadmin/user_upload/ Perfect_Cluster_Program_final_120411.pdf (accessed on 6 March 2020).

35. Pawłyszyn, I. Lean Management concept in the environment of cluster enterprises. Logist. Transp. 2017, $36,43-55$.

36. Błaszczak, A. Więcej Kadry Kierowniczej Wśród Pracowników (Eng. More Management among Employees). 2012. Available online: https://www.rp.pl/artykul/924648-Wiecej-kadry-kierowniczej-wsrod-pracownikow. html (accessed on 6 March 2020). 
37. Randstad. Monitor Rynku Pracy II kw. 2018r (Eng. Labor Market Monitor Q2 2018). 2018. Available online: http: //www.egospodarka.pl/150036,Monitor-Rynku-Pracy-II-kw-2018-r,1,39,1.html (accessed on 5 March 2020).

38. Topolska, K. Wyznaczanie ryzyka łańcuchów Markowa w planowaniu łańcucha dostaw. Cz. 2. (eng. Determining Markov chain risk in supply chain planning. Vol. 2.). Autob. Techn. Ekspl. Syst. Transp. 2017, 6, 1585 .

(C) 2020 by the authors. Licensee MDPI, Basel, Switzerland. This article is an open access article distributed under the terms and conditions of the Creative Commons Attribution (CC BY) license (http://creativecommons.org/licenses/by/4.0/). 